Ist der Magen gesunken, ist die Bauchdecke dünn, dann lässt sich mit einiger Genauigkeit angeben, wo die Kurvaturen liegen; wo aber solche günstigen Umstände fehlen, da heisst es zu Hilfsmitteln greifen. Zur positiven Bestimmung der Magengrenzen bedient man sich dann der Aufblähung, der elektrischen Durchleuchtung oder der Sondenpalpation. Dass durch künstliche Aufblähung, welcher Art sie auch immer ist, oder auch durch die zur Durchleuchtung nothwendige Anfüllung mit Wasser eine Aenderung in der Position des Magens herbeigeführt werden muss, kann nicht in Frage gestellt werden. Das Abtasten des Magens giebt zwar dem geübten Palpator genügenden Aufschlıss über den Stand des Magens, gleichviel wie dick das Fettpolster der Bauchdecken ist, doch ist nicht jedem „das Sehen mit den Fingern" gegeben. So gut aber auch die Palpation zur Bestimmung der grossen Kurvatur ist, so steht sie doch „dein Sehen der Kurvatur" nach. Sowohl die grosse als auch die kleine Kurvatur - die letztere nur bei ptotischem Magen - lässt sich mit ganz freiem Auge wahrnehmen, ohne Zuhilfenalume irgend welcher Instrumente, ohne Aufblähung und ohne Gastrodiaphanie; auch macht dabei die Dicke des Panniculus adiposus gar keinen Unterschied. Nicht allein lassen sich in der hier anzuführenden Weise die Magengrenzen sehen, sondern auch die Grenzen anderer, oberflächlich liegender Organe, wenn sie vergrössert oder ptotisch sind.

Behufs dieser Untersuchung liegt der Patient auf einem gewöhnlichen hohen Untersuchungstische in Rückenlage, das Abdomen selbstverständlich entblösst, und athmet ruhig. Nun stellt sich der Arzt entweder zur Seite oder an die Schultern, so dass er zum Magen entweder hinauf oder hinunter séhen muss, bringt seine Augen auf gleiche Höhe mit dem Niveau des Untersuchungsfeldes und beobachtet die Respirationswellen, die auf dem Abdomen immer, selbst bei sehr fetten Individuen, zu sehen sind. Nach einiger Uebung sieht der Beobachter während der Inspiration unter der Haut eine zarte, feine Linie hingleiten, die er als die Kurvatur des Magens erkennt. Die Stelle, wo diese feine Linie jedes Mal zu Ende der Inspiration aufhört, wird auf der Bauchdecke markirt, und zur Kontrolle wird nun perkuttirt, und zwar in folgender Weise: Der Zeige- und Mittelfinger der linken Hand werden auf das Abdomen so aufgelegt, dass die markirte Linie zwischen diese beiden Finger, die eng an einander gehalten werden, zu liegen kommt, und nun wird über diesen abwechselnd perkutirt, ohne dieselben von der Stelle zu nehmen. Ist die markirte Linie correkt, dann ist der Perkussionsschall unter den beiden Fingern verschieden, Die Perkussion muss ganz leicht ausgefuihrt werden. Auskultatorische Perkussion ist sehr zu empfehlen, wobei aber das Stethoskop nicht geradezu über den Magen gesetzt werden muss; dasselbe kann irgendwo auf dem Abdomen angelegt werden. Wenn noch weitere Zweifel bestehen, ob die markirte Linie der grossen Kurvatur entspricht, dann kann man sehr leicht das Colon aufblähen und die Perkussion in der angegebenen Weise zur Vergewisserung nochmals vornehmen. Der Schall unter dem Zeigefinger entspricht dem Colon, der Schall unter dem Mittelfinger gehört dem Magen an. Sollte das Colon aufgebläht werden, dann unterlasse man ja nicht, die blähende Luft wieder entweichen zu lassen.

IV. Aus der Magenabtheilung der Poliklinik des Oesterreichisch-Ungarischen Hospitals in New-York.

\section{Wie man die Magencontour ohne Hilfsmittel sehen kann.}

Von Dr. Mark I. Knapp, Chefarzt.

Die Inspektion scheint in der physikalischen Untersuchung des Magens eine untergeordnete Stellung einzunehmen. Nur wenig Gewicht wird auf die Mageninspektion gelegt. Kaum ein paar Worte oder höchstens ein paar Sätze werden ihr gewidmet. 